POSTER 7-69

\section{The Effect of Direct Feedback to the Base-Station Physician on the Rate and Appropriateness of ALS Personnel Turning Patient Care over to BLS Personnel}

*Robert E. O'Connor, MD, FACEP, 1,3

Ross E. Megargel, DO, FACEP1-3

1. Department of Emergency Medicine, The Medical Center of Delaware, Wilmington, Delaware

2. EMS Division: Department. of Public Safety, New Castle County; New Castle, Delaware

3. Office of Paramedic Administration, Division of Public Health; Dover, Delaware

Purpose: The prehospital transfer of patient care from Advanced Life Support (ALS) to Basic Life Support (BLS) personnel has been identified as having high medicolegal risk. Such release of patient care to BLS may require medical control input. This study examines the effects of medical-control feedback on the rate and appropriateness of BLS releases.

Methods: The ALS service in this study transports 12,000 patients annually. During 1993, audit data and recommended criteria for BLS releases were circulated to all medical-control physicians. BLS release required the approval of medical control based on the report conveyed from field ALS providers to the medical control physician. ALS providers could request BLS release only when using predetermined criteria based on the patient's condition and complaint. Prehospital care records for all patients released to BLS were reviewed from the final four months of 1992 and from the first four months of 1994. ALS releases were deemed inappropriate in the presence of altered mental status, abnormal vital signs, or a potentially serious complaint. The proportion of cases resulting in BLS release and the proportion of inappropriate BLS releases were compared. Statistical analysis was performed using the Yates corrected Chi-square test for $2 \times 2$ contingency tables.

Results: During the four-month period before the focused feedback, there were 91 BLS releases, 17 $(19.8 \%)$ of which were deemed-inappropriate. During the four-month period after feedback, there were 40 BLS releases, $4(10.0 \%)$ of which were deemed inappropriate. The reduction in the total number of BLS releases was significant $\left(\chi^{2}=19.4, p<0.001\right)$, whereas the reduction in the proportion of inappropriate BLS releases was not $\left(\chi^{2}=1.6,0.10<p<0.25\right.$; power: $\left.79 \%\right)$.

Conclusions: A systematic reduction in the number of BLS releases can be accomplished using focused feedback to medical-control physicians. While the absolute number of inappropriate releases dropped, the relative proportion did not. It is recommended that medicalcontrol physicians strictly adhere to system criteria for BLS releases so as to avoid inappropriate releases.
POSTER 8-16

\section{A Survey of Prehospital Resuscitation Policies in California: Are We Transporting Dead People?}

\author{
*Susan Promes, MD, Gary Tamkin, MD, \\ Kristi T. Koenig, MD, FACEP \\ Highland General Hospital/University of \\ California-San Francisco, Oakland, California
}

Purpose: To assess current practice for paramedic, prehospital resuscitations in California.

Methods: A multiple-choice survey was mailed to all 58 California counties. Follow-up phone calls were made to nonresponders.

Results: Fifty-three of fifty-eight counties $(91 \%)$ responded. Respondents uniformly reported withholding resuscitative efforts for patients who were decapitated/dismembered, had rigor mortis, or body decomposition. Fifty-nine percent of respondents withheld resuscitation for pulseless, nonbreathing (PNB), blunt trauma patients, $38 \%$ for PNB patients with penetrating trauma, and $38 \%$ for patients with a prolonged downtime. Thirty-nine percent of respondents allowed paramedics to discontinue resuscitation in nontraumatic, asystolic cardiac-arrested patients, $61 \%$ in PNB blunt trauma patients, $36 \%$ in PNB penetrating trauma patients, and $43 \%$ in patients with prolonged downtimes and no vital signs after initial resuscitative measures. Nonphysician providers were allowed to declare apparent death in $100 \%$ of responding systems, but $36 \%$ of these required direct medical control. All patients declared in the field were transported by the coroner, either to the nearest hospital, the morgue, or directly to a mortuary. Five counties $(9 \%)$ did not have formal DoNot-Resuscitate policies.

Conclusion: There is diversity in resuscitation policies in California. Despite scientific evidence for the futility of resuscitation attempts under certain circumstances, paramedics continue to transport such PNB patients. With recent emphasis on health-care reform, cost-containment, resource utilization, and safety, EMS districts may need to reanalyze their current practices and attempt to standardize them. 